\title{
EVOLUTION OF THE TREATMENT OF SPINAL CORD INJURIES IN ALGERIA*
}

\author{
By M. Amara, M.D., H. Maiza, M.D., M. Liamini, M.D., \\ Pr.Z. Yagoubi, M.D. \\ Centre Hospitalo Universitaire Rééducation et Réadaptation Fonctionnelle, De \\ Tixeraine, Draria, Algeria.
}

IN 1978, Algeria, with I 8 million inhabitants, had only one Rehabilitation Centre, located in Algiers. This Centre included a spinal cord injury unit of 30 beds, but only for male patients. In 1978, the activity of the unit was almost entirely devoted to the treatment of pressure sores, which had resulted from the prolonged delay of admission of paraplegic patients. From 1978 to 1982 , the treatment of paraplegic patients was modified, in spite of the small number of beds, and the increasing number of admissions. This new orientation included:

the early care of patients with recent injuries; and better prevention of pressure sores, with the help of water mattresses; also

the development of urinary investigations and care.

After 4 years of constant efforts, positive results have been obtained, with the successful prevention of pressure sores, the early acquisition of urinary autonomy, and a reduction of the length of stay in hospital, with a better turn-over of the patients and a better use of the unit.

Our present goal is to maintain these results, and to improve the followup of patients coming from all over the country.

* Summary of paper read at the Annual Scientific Meeting of the International Medical Society of Paraplegia, Athens, Greece. October 1982. 